\title{
Roberto González Le-Feuvre (1928-2013)
}

Durante el tiempo que conocí a mi apreciado colega Roberto González, percibí en él cuatro grandes amores: un amor por la vida, un amor por la música, un amor por la docencia y, last but not least, un amor por su familia.

De su amor por la vida recuerdo nuestros encuentros los domingos en la mañana cuando conversábamos acerca de la necesidad de mantenernos saludables a medida que los años avanzaban. Roberto me confesaba el amor que le tenía a la gimnasia y a la actividad deportiva en general, lo que mantuvo, junto a una actitud positiva y proactiva ante la vida, hasta que una cruel enfermedad lo arrebatara de nosotros.

Su amor por la música se nutrió desde su más temprana edad en el seno de su familia. Según el mismo Roberto señalara a Arturo Carrillo, anterior periodista de la Facultad de Artes, "su padre, un doctor aficionado al violín, y su madre, aficionada al piano, constantemente organizaban reuniones en su casa con otros músicos - profesionales y también aficionados- para disfrutar de las obras clásicas en la intimidad del hogar. En medio de estas sesiones no faltó nunca un violonchelo, instrumento que desde los tres años cautivó a Roberto, según le contaba su madre”. Su padre se llamaba Roberto González Mac-Oliver, apellido materno de origen irlandés o escocés, según se comenta en la familia ${ }^{1}$. Fue una eminencia en el terreno de la medicina, y alcanzó el cargo de Jefe de Urología del Hospital San Borja. Su madre se llamó Alejandrina Le-Feuvre (Lefebre) y ofreció conciertos de violín y piano con el padre de Roberto. En las reuniones sociales y familiares que se realizaban en casa, el pequeño Roberto tocaba junto a su madre y su padre, y con los otros invitados que también participaban en la música. Nuestro músico inició sus estudios sistemáticos a los 11 años de edad, y a los 22 años tomó la decisión de proseguir una carrera profesional como intérprete en violonchelo. Para él la música fue un verdadero "alimento espiritual", en sus palabras, y pocos años antes de su deceso declaró que "un músico nunca se retira".

Su maestro en el violonchelo fue el gran artista Hans Loewe, igualmente versátil en el violonchelo y el oboe. La carrera de Hans Loewe, tanto en el plano de la actividad de la música de cámara como de la música solista marcó un jalón muy importante en la historia de la música chilena de fines de los 40, los 50 y los 60 hasta su fallecimiento acaecido el año 1966.

La carrera de Roberto como músico se vertebró en múltiples senderos. A temprana edad ingresó a la Orquesta Sinfónica de Chile, en la que llegó a ocupar el cargo de Primer Cello Solista. Posteriormente integró en sus comienzos la Orquesta Filarmónica de Chile y la Orquesta de Cámara de la Pontificia Universidad Católica de Chile. Con este último conjunto actuó en una gran cantidad de países sudamericanos y centroamericanos, además de realizar conciertos en Europa y los Estados Unidos.

Además de la música de orquesta, Roberto tuvo una destacada actuación como solista desde el año 1955, cuando participó, junto al también violonchelista Jorge Román y otros músicos, en la Temporada de Verano que realizara ese año la Orquesta Sinfónica de Chile. Tres años más tarde ejecutó un Concierto para chelo y orquesta de Antonio Vivaldi, en una presentación efectuada en la ciudad de Osorno, durante la XVI gira al sur de la Orquesta Sinfónica de Chile, efectuada en abril de 1958. Dos años después participó, nuevamente como solista en la Temporada Oficial 1960 de la Sociedad Juan Sebastián Bach de La Serena, que impulsara con gran denuedo el gran músico mártir Jorge Peña Hen. En sus diversas presentaciones como solista interpretó un amplio y variado repertorio, que incluyera obras del calibre del Triple concierto de Ludwig van Beethoven y el Doble concierto de Johannes Brahms. Un punto de culminación fue el concierto homenaje que le rindiera la Orquesta Sinfónica de Chile el año 2005 junto al gran compositor nacional Juan Orrego-Salas, ocasión en que Roberto interpretó el Concierto para violonchelo y orquesta de Camille Saint-Saëns, bajo la dirección de su hijo Marcelo. Tanto en su repertorio como solista, como en su repertorio de músico de cámara, jamás faltó la música chilena. Es así como efectuó presentaciones de obras de Fernando García, Tomás Lefever, Alejandro Guarello y Adolfo Flores, entre otros creadores nacionales.

Roberto demostró además una fuerte inclinación por hacer música de cámara. Trabajó con pianistas de fuste como Óscar Gacitúa, con quien efectuara, el año 1979, una exitosa gira por varios

1 Agradezco esta información al Sr. Mario González Zapata. 
países de Europa y Estados Unidos, y Elisa Alsina, con quien realizó el año 1987 el ciclo completo de la obra de Ludwig van Beethoven para violonchelo y piano. También actuó con otras figuras del piano, como Verónica Torres y Miguel Ángel Castro, e integró numerosos conjuntos. En 1960 participó,junto con la pianista Giocasta Corma, los violinistas Enrique Iniesta y Fernando Ansaldi, además del violista Manuel Díaz en la Agrupación de Cámara de la Universidad Católica. Los mismos músicos aparecen el año siguiente 1961 como el Quinteto Iniesta en un concierto efectuado en el Salón Helen Wessel del Instituto Chileno-Norteamericano de Cultura.

El fallecimiento de su maestro Hans Loewe el año 1966 dejó un gran vacío en el Cuarteto Santiago, en el que había participado durante treinta años junto a los violinistas Stefan Tertz y Ubaldo Grazioli además de Raúl Martínez en la viola. Roberto fue llamado por los integrantes del Cuarteto a ocupar la plaza del violonchelo, lo que permitió que el año 1969, tres años después del fallecimiento de Hans Loewe, el Cuarteto hiciera su reaparición en público. Esta se efectuó en el auditorio del Instituto Chileno-Alemán de Cultura, con el ciclo de los tres cuartetos para cuerdas y piano de Johannes Brahms y la participación de la gran artista Elvira Savi en la parte del piano. El 14 de julio de ese año el Cuarteto Santiago inició un ciclo memorable con la presentación de la totalidad de los Cuartetos de Beethoven. Este ciclo causó un profundo impacto en todos los que tuvimos el privilegio de escucharlo acompañado de las versadas palabras del gran musicólogo hispano-chileno Vicente Salas Viu. Al año siguiente (1970) el Cuarteto Santiago repitió el ciclo con motivo del bicentenario del nacimiento del gran maestro de Bonn, el que fuera celebrado en esa época en todo el mundo incluyendo por supuesto a Chile.

Su quehacer de excelencia en el campo de la música le granjeó numerosas distinciones. En 1984 fue invitado por el maestro Harvey Shapiro a su curso en la prestigiosa Julliard School of Music de Nueva York. El año 1991 integró el jurado del XVII Concurso de Ejecución Musical Dr. Luis Sigall, junto al artista Jorge Román y a violonchelistas de relevancia mundial como Christine Walevska y Bernard Michelin. La Universidad de Chile lo nombró en la máxima jerarquía de la carrera académica ordinaria y la Facultad de Artes lo designó como integrante del Comité Superior de Evaluación Académica, que preside el profesor Hanns Stein. Compartí en el seno de este Comité con el profesor González y tuve la oportunidad de escuchar su palabra siempre clara y firme, pero también juiciosa y mesurada.

Fue un destacado docente tanto en el Instituto de Música de la Pontificia Universidad Católica como en la Facultad de Artes de la Universidad de Chile. Al respecto, resulta de interés evocar el concierto efectuado en la Sala Isidora Zegers el jueves 20 de noviembre de 2011. En él participaron los alumnos de la cátedra de violonchelo a cargo de Roberto, con obras de Johann Sebastian Bach, Robert Schumann, Camille Saint-Saens, Antonio Vivaldi, Jean Barriére y Marin Marais. Participaron, en orden de aparición, Belén Ramos, Victoria Canales, Isidora O'Ryan, Camila Bahamondes, Felipe Rosas, Cristián López, Cindy Osorio, Paulina Weir-Hopff y Miguel Arredondo. Como ellos, muchos otros estudiantes se beneficiaron de las sabias lecciones del maestro Roberto González.

La mejor prueba de su amor a su familia lo constituye la organización, a mediados de 2005, de la Agrupación Fammusic, con sus hijas e hijos. Esta actividad se inscribe en una tradición que es muy característica en la historia de la música en Chile. Se inicia con la familia Guzmán, de la que surge el gran compositor-pianista decimonónico chileno Federico Guzmán, y continúa durante el siglo XX con las familias de Marta Canales, de don Alfonso Letelier, de Margot Loyola y de Violeta Parra, por solo mencionar algunas de ellas. Esta misma institución (la familia) fue algo decisivo en la formación y el quehacer de este gran hombre y este gran artista, que ya forma parte importante de la historia de la música de nuestro país.

Luis Merino Montero 